\title{
Informing Parents with the Victorian Education Ultranet
}

\author{
Arthur Tatnall and Eva Dakich \\ Victoria University, Melbourne, Australia
}

Arthur.Tatnall@vu.edu.au, Eva.Dakich@vu.edu.au

\begin{abstract}
Parents of school children want to be well informed and know as much as possible about their children's school and how their children are progressing at school. In mid-2010 in Victoria, Australia the Department of Education and Early Childhood Development launched the Ultranet, a new web-based product designed to support knowledge sharing, curriculum delivery and online learning and teaching. This paper describes the Ultranet, how it has been developed and how it is to be used to inform parents, but as the Ultranet was only beginning to come into operation in late 2010 it has not been possible to include any research findings. With its facilities to inform parents and to offer collaboration features to teachers, the Ultranet appears to be something not attempted anywhere before. The paper is thus a theoretical one discussing the Ultranet's design and possibilities, and is framed by using both an Actor-Network Theory (ANT) and Siemens' Theory of Connectivism. Later papers will examine how the Ultranet performs in practice.
\end{abstract}

Keywords: Informing communities, Ultranet, Web 2.0 technologies, knowledge sharing, school communities, curriculum delivery, online learning, actor-network theory, connectivism.

\section{Introduction}

Traditionally in Australia, parents have been informed of their children's progress at school through the use of school reports, parent-teacher evenings and an annual 'Open Day'. All parents want to know both what their children are doing at school and how well they are progressing. They want to know as much about the school, where their children spend so much time, as possible. In many cases they would also like to be involved in some of the school's activities, whether this means going as a helper on a school excursion, serving in the school canteen or doing some cleanup activities in the school yard over the weekend. At this point the Ultranet enters the scene.

Several years ago the Victorian Government conceived an online system for informing school communities using web-based technology. It would support knowledge sharing across Victorian government schools and also provide facilities for informing parents and for curriculum delivery and online learning and teaching (Department of Education and Early Childhood Development

Material published as part of this publication, either on-line or in print, is copyrighted by the Informing Science Institute. Permission to make digital or paper copy of part or all of these works for personal or classroom use is granted without fee provided that the copies are not made or distributed for profit or commercial advantage AND that copies 1) bear this notice in full and 2) give the full citation on the first page. It is permissible to abstract these works so long as credit is given. To copy in all other cases or to republish or to post on a server or to redistribute to lists requires specific permission and payment of a fee. Contact Publisher@InformingScience.org to request redistribution permission.
2010). The Victorian Government's

Department of Education and Early

Childhood Development (DEECD)

describes the Ultranet as "a student centred electronic learning environment that supports high quality learning and teaching, connects students, teachers and parents and enables efficient knowledge transfer" (Department of Education and Early Childhood Development 2010). The $\$ 60$ million Ultranet, which is es- 
sentially an extended intranet/extranet was rolled out to all Government schools in September 2010.

The Ultranet is the result of several years of work. In 2004, the DEECD began research and development of a project to "produce a 'proof of concept' student-centric ICT system, called Students@Centre, to support online teaching and learning, curriculum delivery and knowledge management in Victorian government schools" (Department of Education and Early Childhood Development, 2010). Educational researchers from the University of Melbourne conducted the study and, in 2006, published a report (Griffin and Woods 2006) that lead to the construction and implementation of the Ultranet.

The Minister for Education notes that: "The Victorian Government is committed to giving every child every opportunity to experience the full potential of online learning, collaboration and information sharing" and describes the Ultranet as the "Victorian Government's biggest investments in information and communication technology in our public education system" (Pike 2010).

\section{The Victorian Government Schools' Ultranet}

The Ultranet has many of the features of a business extranet in that it is closed to people outside the Victorian government school community and requires a username and password to gain access. One major difference to a business extranet, however, is the Ultranet's large size: its users will include over 540,000 students (and their parents) in 1,555 government schools along with their 40,000 teachers (Australian Bureau of Statistics 2010; Department of Education and Early Childhood Development, 2010).

(It should be noted that the Ultranet is not available to non-government schools in Victoria - the 489 Catholic Schools and 218 Independent Schools.)

The Ultranet's underlying technology is based mainly on Oracle and it incorporates various Web 2.0 technologies. The Ultranet is thus a closed, secure place on the Internet, accessible by students, teachers and parents /guardians from the school community. It offers a space that students, parents and teachers can connect to anywhere, anytime they have access to a computer.

- The Ultranet has been designed to allow students to access personalised learning activities and to keep an ongoing record of these activities. Students will be able to collaborate and communicate with students from their own school and with

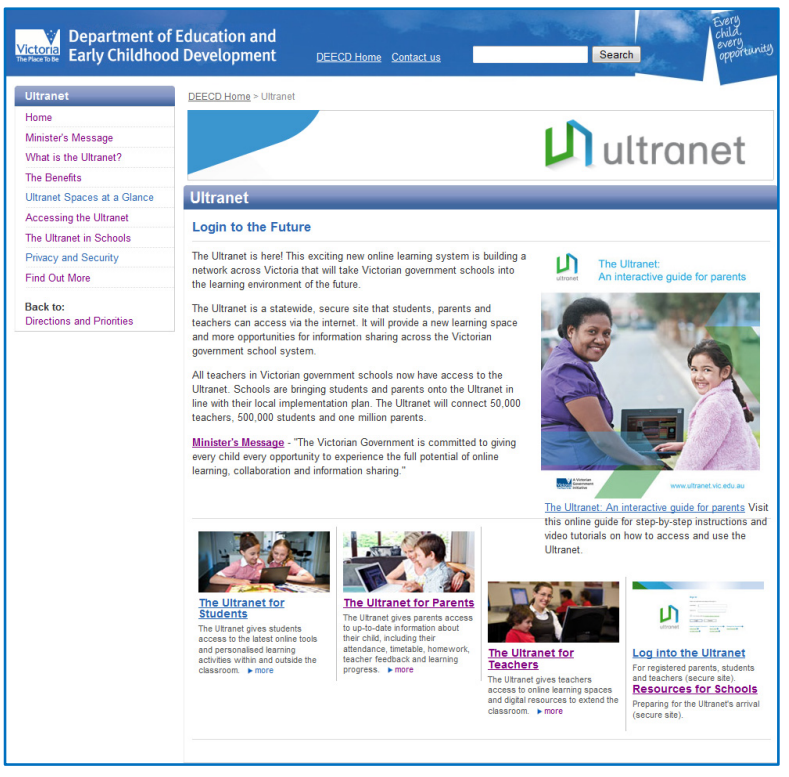

Figure 1: The Ultranet (http://www.education.vic.gov.au /about/directions/Ultranet/default.htm) students from other Victorian government schools. They will be able to create learning portfolios and use online communication tools such as wikis, blogs and discussion boards.

- Teachers can create curriculum plans, collaborate with other teachers, monitor student progress and provide student assessment. The Ultranet will provide support for teachers to collaborate and to share professional practice and interests with colleagues from around Victoria.

- Parents will be able to access the Ultranet to see information that will help them keep up-todate with their child's learning. This dynamic profile of their child will include attendance re- 
cords, timetables, test results and learning progress, homework activities and tasks and teacher feedback so providing another way for parents to support their child at school

The Ultranet has many of the features found in learning management systems, such as Blackboard, but also has other features intended to inform parents about their child's education and about the school they attend. While web-based learning systems, like Blackboard, are used around the world the Ultranet appears to be the first attempt to include additional features to inform parents and to provide teachers with facilities to work collaboratively.

The documentation provided to students, teachers and parents for the Ultranet speaks of three different types of entity that they will need to understand to use it. The Ultranet makes use of Spaces, which are really mini-websites, Icons that help you to get to the appropriate Space, and Applications that 'bring the Space to life'.

Each of the different types of specially designed 'Space' is intended to allow different information to be accessed and different learning activities to be performed. Each Space is classified by its accessibility into one of the following categories:

- Me spaces are private spaces accessible only by the owner

- We spaces are shared spaces that can be seen by those with permission to be in that space

- See Spaces are public, open access spaces that can be seen by the whole world.

Clearly security and privacy will be very important issues here. The Ultranet website (Department of Education and Early Childhood Development, 2010) notes that this is a 'closed community' with controlled access and that it has a very specific educational purpose as everything that students can do on the Ultranet is intended to support their learning. It lists the following measures to ensure security and privacy protection:

- "to access the Ultranet, authorised users must log in with a secure, complex password

- there are rules around who can access what information, and the types of users that can access each type of 'space' within the Ultranet

- no anonymous postings are possible in the Ultranet - all postings are logged and audited

- all learning communities on the Ultranet must be moderated by a teacher

- all users can report inappropriate content

- in addition to the filtered internet service available in each school, the Ultranet also contains filters for bad language."

(Department of Education and Early Childhood Development, 2010)

The Ultranet will be released in two stages and consists of the following Spaces, all of which (except Learning Tasks and Learner Profile) will be available in Release 1:

1. Home is a personalised page for students, parents and teachers where they can see school or community notices and where students and teachers can add their favourite applications. (This is a Me space.)

2. eXpress Space is a personal We space for students and teachers to capture, share and reflect on their learning. The student eXpress Space includes spaces for their Learning Portfolio and Learning Goals.

3. Design is a space where teachers can plan, create and collaborate with colleagues within and across schools and design curriculum and student learning activities. This space is not available to students.

4. Community is a space where students, parents and teachers will find information about school news and events and where they can be involved in school-based groups, clubs or activities. (This is a We space.) 
5. Collaborative Learning. In this space students can take part in online learning activities set up by their teachers using a range of Web 2.0 tools including blogs, wikis, message boards and polls. (This is a We space.)

6. Learner Profile is a We space where students, their parents and teachers can view a detailed profile of their individual learning progress. Information about each child will build up over time, creating an ongoing record. (Only available in Release 2.)

7. Learning Tasks. Here teachers can plan, deliver and assess learning activities, and students can view and submit learning tasks. (This is a We space, only available in Release 2.)

8. My Content is a space where teachers and students can store and search for personal, school and quality-assured digital learning resources. (This is a We space.)

9. Connect allows students to find reviewed websites and online activities.

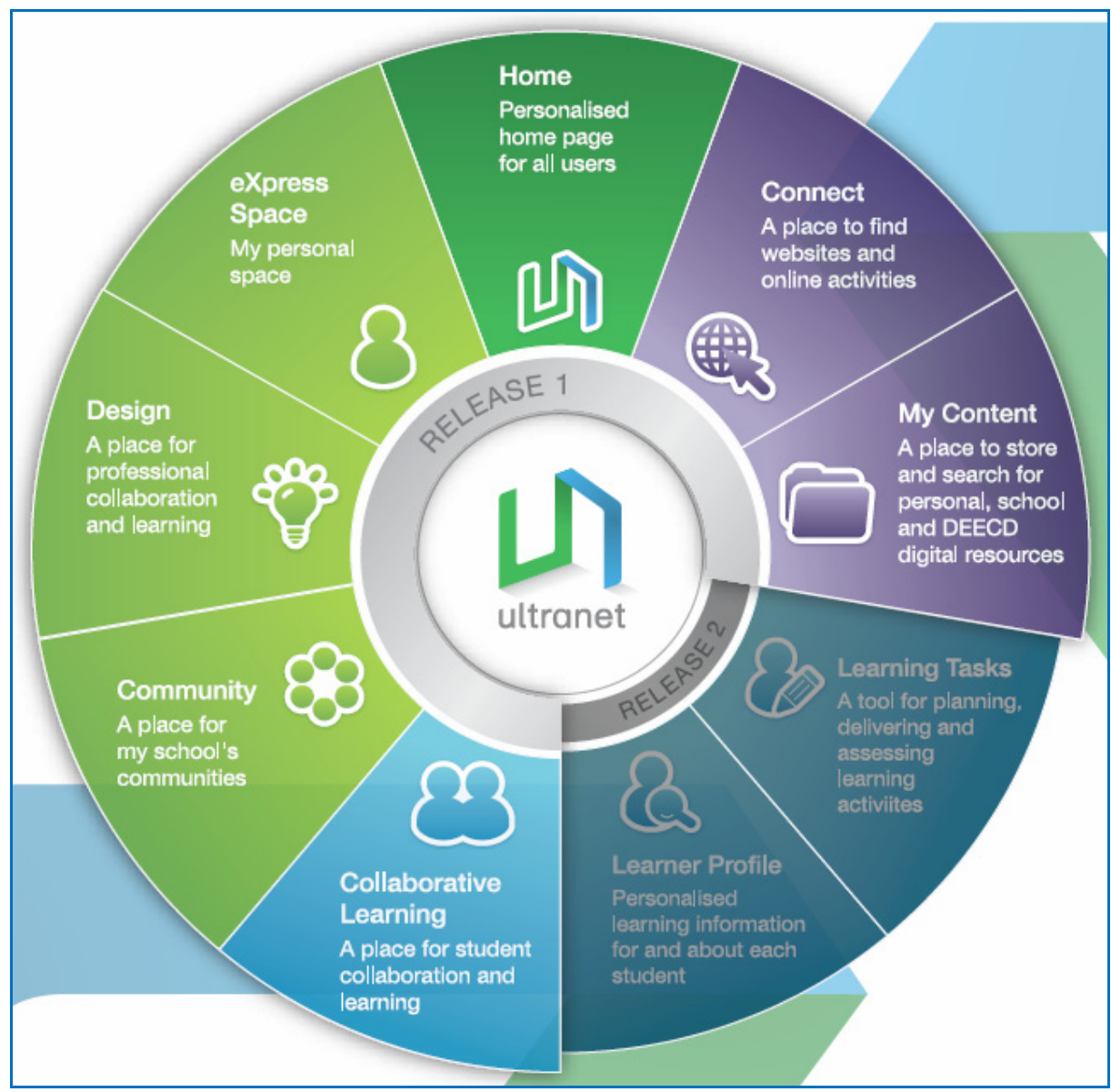

Figure 2: 'Spaces' on the Ultranet

It also contains:

a) Actions - a pop-up menu from which to choose applications and to customise each space.

b) Utilities - a pop-up menu that provides access to a number of utilities including e-mail.

(Department of Education and Early Childhood Development, 2010) 
DEECD's website notes that specifically, the Ultranet is designed to:

- "Enable parents to become full partners in their child's education, giving them online access to their child's homework, attendance, assessment, curriculum and teacher feedback at any time.

- Ensure that every child will have a complete record of achievement across all years of schooling.

- Give students their own online workspaces, personally tailored education programs, direct feedback from teachers and better access to curriculum.

- Enable students in remote schools to access specialised curriculum and podcast classes from schools that excel in various subject areas.

- Allow students to learn in an environment that will ensure that they have the cutting edge ICT skills they will need in the $21^{\text {st }}$ century workforce.

- Reduce the administrative burden for teachers and schools by using the Ultranet for recording attendance, school reports, timetabling and school events, to pool schools' resources and give teachers access to a vast central database of classroom resources."

(Department of Education and Early Childhood Development, 2010)

\section{Web 2.0 Technologies in Education}

Web 2.0 technologies have become the most popular avenues of social interaction in the new millennium. Web-based applications such as Myspace, Facebook, Skype and Twitter are considered to be the main channels of communicating with friends and family beyond the traditional boundaries of space and time. The so-called digital natives are leading the communication revolution, leaving behind their teachers and parents who are either less technologically savvy or just more cautious when it comes to sharing personal information in cyberspace. While students spend most of their spare time posting information on Facebook and Twitter about every aspect of their lives, their parents and teachers worry about the social and legal consequences of using these recreational technologies. It is well-known from popular media that children and youth are often vulnerable to undesirable social influences, such as misinformation, inappropriate content and relationship when exploring the loosely regulated virtual world. Banning these social networking sites is standard practice in Victorian primary and secondary schools. While most schools shy away from recreational Web 2.0 applications many of them have started using wikis and blogs as well as YouTube to enhance student learning through new technologies. YouTube has become a very popular visual aid to teachers' repertoires, bringing the power of video pedagogy into the classroom. Blogs have been successfully used for diarising and journal writing while wikis are being utilized by teachers to facilitate collaboration and cooperative knowledge construction. However there are several significant issues that have not been resolved to date when using Web 2.0 technologies which are hindering widespread adoption of these online resources. The following questions have been at the centre of current debates in education worldwide:

- How do we protect privacy and confidentiality of information?

- How do we manage issues related to copyright and intellectual property when sharing digital content?

- How do we protect children and youth from possible psychological, social and legal risks?

The Ultranet seems to bring some answers to these questions by providing a safe and protected environment for interaction, exploration and collaboration among students, teachers, parents and the wider community. The so called Spaces will provide personalized pages for students, parents and teachers through which they can securely access and store digital content and can interact with each other without compromising the privacy or confidentiality of information. The Spaces 
will harness the potential of popular Web 2.0 technologies by incorporating wikis, blogs, instant messaging and conferencing to allow for both synchronous and asynchronous information exchange and collaboration between the various stakeholders. Drawing on the power of Web 2.0 technologies, parents will be able to use a number of Spaces such as Home, Learner Profile and Community to stay informed about their children's school performance as well as to be involved in various groups and activities. It is expected that these new ways of informing and engaging parents will strengthen parental involvement in schools resulting in improved student outcomes and stronger partnerships between schools and communities.

\section{Actor-Network Theory and the Ultranet}

Any study of the Ultranet will, of necessity, need to look at the contributions and interactions of human actors but also of those of non-human actors including the technology itself. It is important to think of the Ultranet as an actor and not just an artefact. Actor-Network Theory (ANT), or the "sociology of translations" (Callon 1986; Law 1992) was designed as an approach to sociotechnical research that would address the need to treat the contributions of both human and nonhuman actors fairly and in the same way (Callon 1986), and was developed to analyse situations where separation of human and non-human elements is difficult ( Callon 1997; Latour 1993; Tatnall 2009; Tatnall and Gilding 1999). ANT investigates the construction and maintenance of networks made up of both human and non-human actors and attempts impartiality towards all actors in consideration, whether human or non-human, and makes no distinction in approach between the social, the natural and the technological.

"The rule which we must respect is not to change registers when we move from the technical to the social aspects of the problem studied." (Callon, 1986, p. 200)

The first step normally undertaken in an ANT analysis is to identify the actors involved, but first we should consider what entities we need to think of as actors. Law (1987) describes an actor as any human or non-human entity that is able to make its presence individually felt by other actors, and so this term is applied to any entity that has an effect on the situation being examined. An actor is made up only of its interactions with these other actors (de Vries, 1995) and Law (1992) notes that an actor thus consists of an association of heterogeneous elements constituting a network (Tatnall, 2010). Callon (1986) also argues that an actor can also, at times, be considered as a black box as we do not always need to see the details and operation of the network of interactions that is inside it.

It has not been possible to commence a detailed research project on the Ultranet at this stage as it has been in operation only a very short time. Actor-network theory does, however, offer a number of pointers to future Ultranet research. In relation to an investigation of the Ultranet project we can easily identify the following actors: Students, Teachers, School Principals, Parents, Schools, School Councils, the Ultranet Developer, Broadband Connections, School Computers, Home Computers, DEECD and the Victorian Government and the Ultranet itself. The parts likely to be played by human actors such as students, parents and teachers are fairly obvious, but those of some of the other actors are less clear. What part will DEECD and the Victorian Government play? The answer is probably in the provision of funds and determination of future directions, but they may do more. How will School Councils interact with Parents in relation to the Ultranet? What about School Principals?

The Ultranet itself will, to most people, be best considered as a black box that performs the function of providing this service, but if we want to look at issues like built-in privacy and security measures or the user interface we will need to lift the lid and see what is inside this black box: to see how the Ultranet actually works. What effect will the computers used at school and at home have on the project? Will it make a difference if the students use a Mac at school and a PC at 
home? In ANT terms the computer is an actor as it has an effect on the way that the Ultranet is accessed. The broadband link is also relevant as if this does not work then access to the Ultranet will be broken, if it runs slowly then access speed will be slow and users may give up on its use. What about the Ultranet developer? Will they play an on-going role? These are just some of the questions relating to the interactions of these actors.

Another slant we can consider as thinking of the Ultranet project as an example of technological innovation (Tatnall, 2009a, 2009b, 2009c). Actor-network theory sees the process of innovation in terms of translation from one state to another, and Callon (1986) suggests that the process of translation has four aspects or "moments": Problematisation, Interessement, Enrolment and Mobilisation.

In problematisation, one or more key actors attempts to define the nature of the problem and the roles of other actors so that these key actors are seen as having the answer, and being indispensable to the solution of the problem (Tatnall, 2010). In other words, the problem is re-defined, or translated, in terms of solutions offered by these actors who then attempt to establish themselves as an 'obligatory point of passage' (Callon, 1986) which must be negotiated as part of its solution. In the case of the Ultranet it is unlikely that all the actors will see its use in the same way, and some actors will want to try to persuade others that their view of its operation and use is the one that should be adopted. These key actors will then attempt interessement, which is a series of processes that attempts to impose the identities and roles defined in the problematisation on the other actors. They will attempt to convince students, parents and teachers to make what they consider to be 'good use' of it. How successful they will be only time will tell.

\section{Creating New Social Networks for Lifelong Learning}

Another important theoretical perspective that contributes to the understanding of the social relevance of the Ultranet is Connectivism offered by George Siemens (2004). Connectivism provides a rationale for the main objectives of Ultranet, which are developing key competencies for the digital society through online learning, collaboration and information sharing, and maintaining effective flow of information among various stakeholders in education. According to Siemens:

"Information flow within an organization is an important element in organizational effectiveness. In a knowledge economy, the flow of information is the equivalent of the oil pipe in an industrial economy. Creating, preserving, and utilizing information flow should be a key organizational activity. Knowledge flow can be likened to a river that meanders through the ecology of an organization. In certain areas, the river pools and in other areas it ebbs. The health of the learning ecology of the organization depends on effective nurturing of information flow." (Siemens, 2004, p. 6)

Siemens argues that the half-life of knowledge has changed, and that the amount of knowledge generated in the past years, as well as the rate at which new knowledge is being produced calls for "new methods of deploying instruction" (Siemens, 2004, p. 1), as well as innovative ways of understanding the relationships between learners, learning and learning environments. The Ultranet does exactly this; it offers new avenues for the delivery of information and knowledge construction and provides opportunities for the development of new social practices leading to authentic patterns of lifelong learning.

In order to understand these emerging patterns of lifelong learning, Siemens calls for new epistemic foundations and explanations of learning. In his opinion learners will not stay in a single field over the course of their life. As a consequence informal learning will become an important aspect of lifelong education. Learning and work cannot be viewed as separate activities, as learning occurs not only in formal educational settings, but also in communities of practice where learners develop new skills and understandings through personal interactions and work-related 
tasks. The Ultranet will open up opportunities for blending traditional and new learning environments and will allow students, parents and community stakeholders to develop sustainable pathways between learning and work through augmented social networks.

According to Siemens new technologies shape and define our thinking processes and aid effective knowledge management and organisational aspects of learning. In his opinion learning becomes a process of self-organisation, which can happen at a personal level, or within institutional and other social networks and/or environments. He adopts Barabási's (2003) explanation of networks as "connections between entities", and argues that social networks behave like computer networks and that their participants (representing nodes) can be connected to an "integrated whole". Siemens defined learning as "actionable knowledge" that can "reside outside of ourselves (within an organisation or a database), is focused on connecting specialised information sets, and the connections that enable us to learn more are more important than our current state of knowing" (Barabási, 2003, p. 5).

The Ultranet as a technological innovation is expected to facilitate the emergence of new social networks that will become self-organised consumers of information as well as constructors of new content through their capacity to access, nurture, and maintain information and knowledge flow. Parents and community stakeholders will be part of these networks that will enable them to communicate and collaborate with teachers, other parents and community stakeholders in order to gain a better understanding of what schools are trying to achieve.

\section{Informing Parents and the Education Community}

All websites have some function to inform their clients or customers in some way, but most do not customise their information to such a specific audience as does the Ultranet. An example of a website designed to inform parents and the community about Australian schools is the MySchool website (Australian Curriculum Assessment and Reporting Authority, 2010) recently set up by the Australian Commonwealth Government. (Although school education in Australia is a State responsibility, the Federal Government is also a significant actor in providing information and targeted grants to schools for specific projects.) Early in 2010 the Australian Government launched this new e-government initiative (Gillard, 2010) that contains information about each of Australia's ten thousand primary and secondary schools, including: the number of students and the number of teachers at the school and how the school is performing in national literacy and numeracy testing. The ideas of setting up this web site was so that: "parents and school communities would be able to compare their school's results with neighbouring schools and up to 60 statistically similar schools" (Gillard, 2010) to see which schools are doing well and which schools are not. A recent article in the Melbourne Age newspaper (Harrison, 2010) indicated that consideration is being given to enhancing the My School web site by the inclusion of data about income, occupation and education level of students' families so that more valid socio-economic comparisons between schools can be made.

MySchool is quite different to the Ultranet, however, in that it provides general information about all Australian schools, and not about particular students, to anyone who wants to see this and so has no need for password security. The aim of the site is to allow parents to compare potential schools where they may want to send their children. MySchool also shows information on all Australian schools, both government and non-government whereas the Ultranet includes only Victorian government schools and aims to inform specific parents of their own school children in this way. 

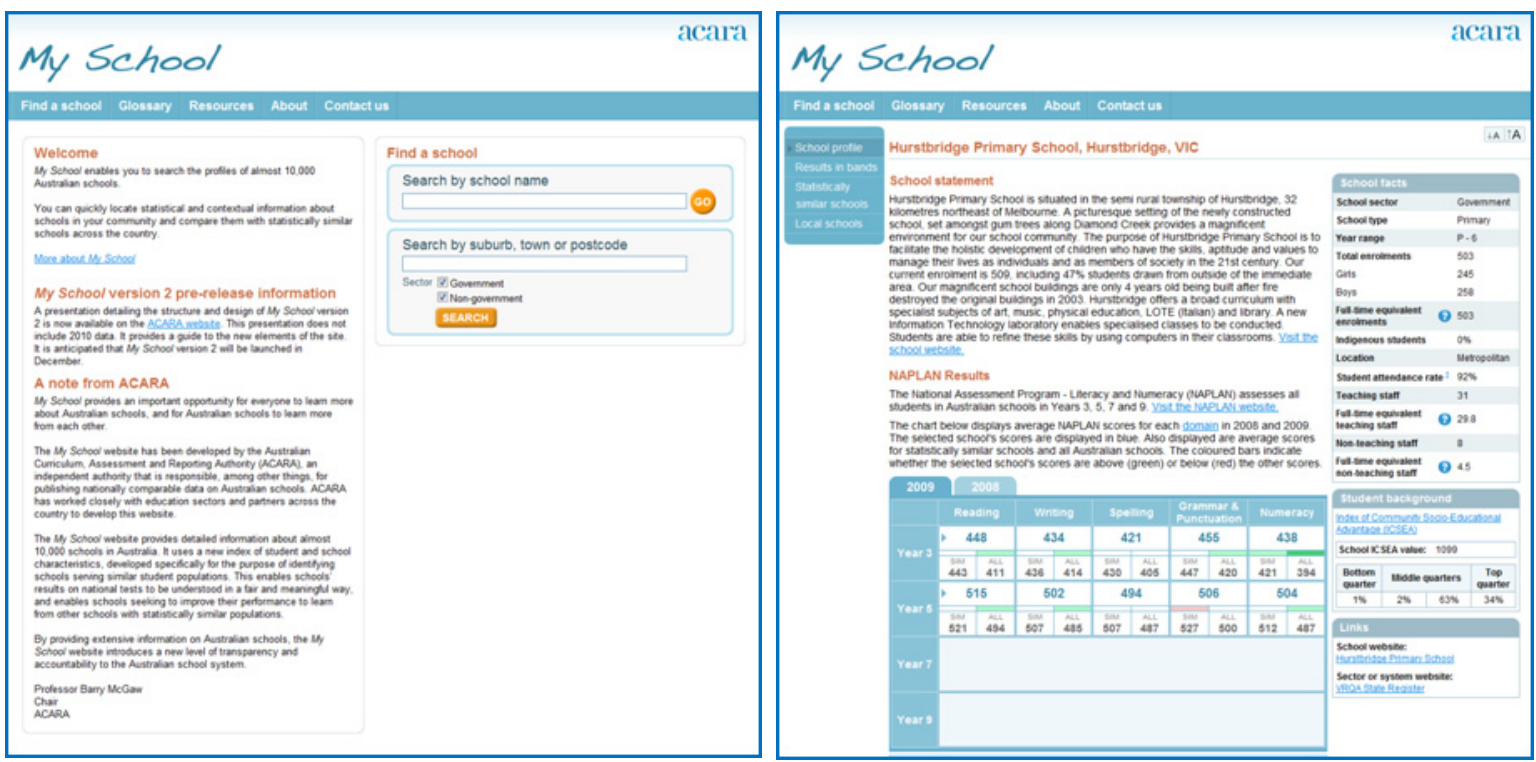

Figure 3: MySchool website (http://www.myschool.edu.au/) and information for Hurstbridge Primary School

Although many websites and a number of business extranets are set up to provide general information, some extranets are designed to give quite specific information to particular clients in a somewhat similar manner to the Ultranet. One example of this is found in courier/delivery companies such as DHL and FedEx that provide a delivery tracking service to their customers. This information is very specific to the customer as they have to enter the waybill number provided by the company before they can see details of the delivery. Amazon.com and several other similar companies also provide this type of personalised service.
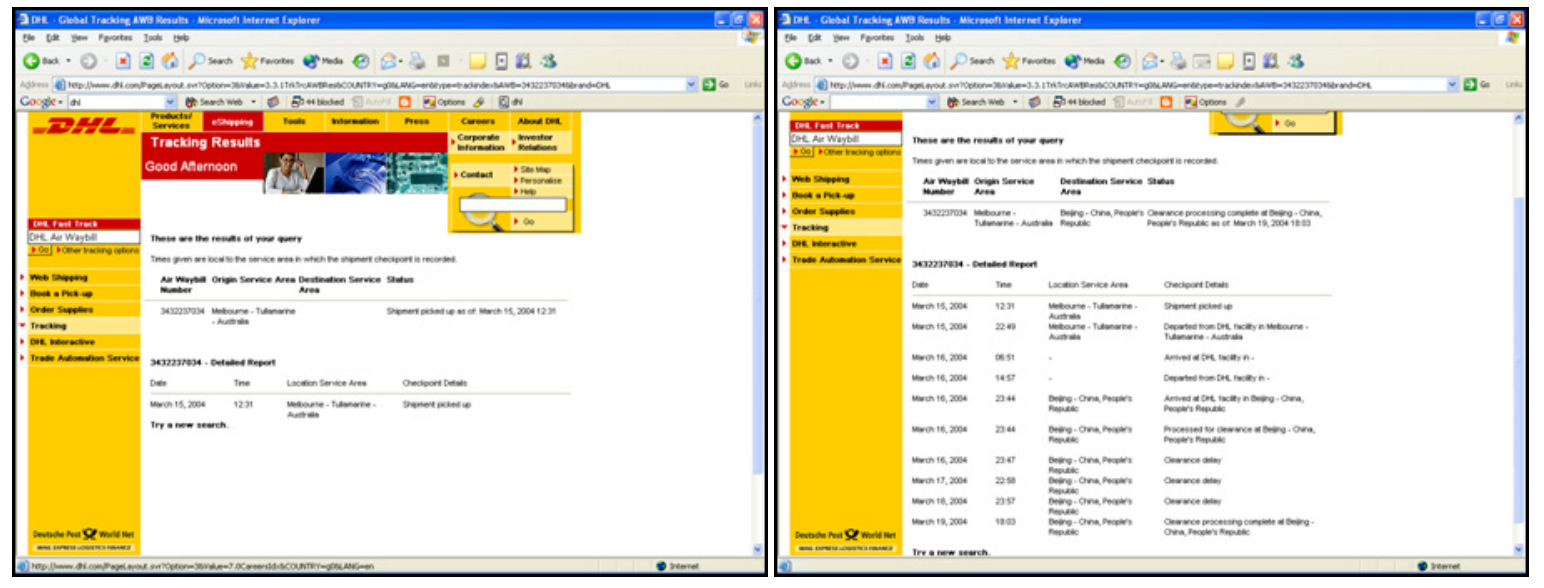

Figure 4: DHL extranet - information on tracking the delivery of books from Melbourne to Beijing

The Ultranet is not just a single connection between government and the public, as is MySchool, but an attempt to create a mutually supporting educational community.

\section{Building Effective Partnerships between Schools Families and Communities}

According to The National Family-School Partnerships Framework (Department of Education Employment and Workplace Realtions, 2008) families have a significant role in the education of 
Informing School Communities with the Victorian Education Ultranet

their children. Schools need to recognise the primary role of families in their children's education and work towards sustainable and effective partnerships with parents. New technologies allow for a greater and more convenient family involvement when compared to traditional ways of interacting with families. They introduce new practices of reaching out to families and can contribute to richer and more immediate interaction between teachers, parents and community stakeholders.

Relying on a broad range of technologies described in this paper, the Ultranet will allow for multifaceted parental engagement that will provide the foundations to successful-school-familycommunity partnerships. According to Epstein et al. (2009) these involve:

Parenting: Assist families with parenting and child-rearing skills, understanding child and adolescent development, and setting home conditions that support children as students at each age and grade level. Assist schools in understanding families.

Communicating: Communicate with families about school programs and student progress through effective school-to-home and home-to-school communications.

Volunteering: Improve recruitment, training, work, and schedules to involve families as volunteers and audiences at school or in other locations to support students and school programs.

Learning at home: Involve families with their children in learning activities at home, including homework and other curriculum-related activities and decisions

Decision making: Include families as participants in school decisions, governance, and advocacy through PTA/PTO, school councils, committees, action teams, and other parent organizations.

Collaborating with community: Coordinate resources and services for students, families, and the school with businesses, agencies, and other groups, and provide services to the community. (Epstein, Sanders et al. 2009 :47)

\section{Conclusion}

The Victorian Schools Ultranet has only just commenced operation, but can be seen to offer many possibilities for informing parents about what their children are doing at school and about their progress, as well as informing parents about the school itself. It also offers possibilities for useful interactions of many types between all members of school education communities.

The need to inform parents of school children about the child's school and educational progress is something that governments and education authorities have always acknowledged. Technology like the Ultranet and the MySchool website offers new ways to do this, akin to aspects of Web 2.0 technologies like Facebook and MySpace that should appeal to the $21^{\text {st }}$ century parent. It will be interesting to follow the progress of these technologies as they fully develop over the next year or two, and to see whether the various actors make appropriate connections to get the most out of the technology.

It is also interesting to consider whether technology of this type could also be used to inform other groups. It could, for instance be used at universities and schools to track the progress of scholarship holders. A system could be built to allow scholarship providers the facility to follow the test results and attendance of these students. Would this be an appropriate use of such technologies, or would it be seen as unwarranted interference in the private lives of these students? What about a system to inform other groups such as potential employers of university students, the courses of study they are undertaking and their results? The answer, of course, is that what is technologically possible is not always socially desirable. 


\section{References}

Australian Bureau of Statistics. (2010). Statistics Victoria, Mar 2010. Retrieved November 2010, from http://www.abs.gov.au/AUSSTATS/abs@.nsf/Lookup/1100.2Main+Features3Mar+2010

Australian Curriculum Assessment and Reporting Authority. (2010). My school. Retrieved November 2010, from http://www.myschool.edu.au/SchoolSearch.aspx

Barabási, A. L. (2003). Linked: How everything is connected to everything else and what it means for business, science and everyday life. New York: Penguin Group.

Callon, M. (1986). The sociology of an actor-network: The case of the electric vehicle. In M. Callon, J. Law, \& A. Rip, Mapping the dynamics of science and technology (pp. 19-34). London: Macmillan Press.

Callon, M. (1986). Some elements of a sociology of translation: Domestication of the scallops and the fishermen of St Brieuc Bay. In J. Law, Power, action \& belief. A new sociology of knowledge?(pp. 196-229). London: Routledge \& Kegan Paul.

Callon, M. (1997, 31 July). Actor-network theory - The market test (draft). Actor network and after workshop. Retrieved from http://www.keele.ac.uk/depts/stt/stt/ant/callon.htm

de Vries, G. (1995). Should we send Collins and Latour to Dayton, Ohio? EASST Review, 14(4).

Department of Education and Early Childhood Development. (2010). Students@Centre-Research and development. Retrieved May 2010, from http://www.education.vic.gov.au/management/ultranet/research.htm

Department of Education and Early Childhood Development. (2010). Summary statistics for Victorian schools. Retrieved November 2010, from http://www.education.vic.gov.au/about/publications/newsinfo/factsandfigures.htm

Department of Education and Early Childhood Development. (2010). Ultranet. Retrieved May 2010, from http://www.education.vic.gov.au/management/ultranet/default.htm

Department of Education and Early Childhood Development. (2010). Ultranet - Getting started (Release 1), Resources for Teachers. Department of Education and Early Childhood Development. Melbourne, Department of Education and Early Childhood Development,.

Department of Education and Early Childhood Development. (2010).Ultranet - Students@Centre Trial. Retrieved November 2010, from http://www.education.vic.gov.au/about/directions/ultranet/trial.htm

Department of Education Employment and Workplace Realtions. (2008). Family-school partnerships framework: A guide for schools and families. Retrieved from http://www.dest.gov.au/NR/rdonlyres/A1443756-85CE-4BDD-AED5644A25C337F1/24590/FamilySchoolPartnershipsFrameworkFINAL.pdf

Epstein, J. L., Sanders, M. G., et al. (2009). School, family and community partnerships, Your handbook for action. Corwin Press.

Gillard, J. (2010). My school website launched. Retrieved May 2010, from http://www.deewr.gov.au/ministers/gillard/media/releases/pages/article 100128 102905.aspx

Griffin, P., \& Woods, K. (2006). Evaluation of the pilot implementation of the Student@Centre Ultranet in Victorian schools. Melbourne: The University of Melbourne.

Harrison, D. (2010). Data for schools' site may expand. The Age, p. 8. Melbourne.

Latour, B. (1993). We have never been modern. Cambridge, MA: Harvester University Press.

Law, J. (1987). Technology and heterogeneous engineering: The case of Portuguese expansion. In W. E. Bijker, T. P. Hughes, \& T. J. Pinch, The social construction of technological systems: New directions in the sociology and history of technology (pp. 111-134). Cambridge, MA: MIT Press. 
Informing School Communities with the Victorian Education Ultranet

Law, J. (1992). Notes on the theory of the actor-network: Ordering, strategy and heterogeneity. Systems Practice, 5(4), 379-393.

Pike, B. (2010). Ultranet - Minister's message. Retrieved November 2010, from http://www.education.vic.gov.au/about/directions/ultranet/minister.htm

Siemens, G. (2004). Connectivism: A learning theory for the digital age. Retrieved August, 2005, from www.elearningspace.org/Articles/connectivism.htm

Tatnall, A. (2009a). Information systems, technology adoption and innovation translation. International Journal of Actor-Network Theory and Technological Innovation, 1(1), 59-74.

Tatnall, A. (2009b). Innovation translation and innovation diffusion: A comparison of two different approaches to theorising technological innovation. International Journal of Actor-Network Theory and Technological Innovation, 1(2), 67-74.

Tatnall, A. (2009c). Innovation translation as a research approach to theorising information systems implementation. International Journal of Networking and Virtual Organisations, 6(1), 64-76.

Tatnall, A. (2010). Using actor-network theory to understand the process of information systems curriculum innovation. Education and Information Technologies, 15(4), 239-254. [Special Issue on Information Systems Curriculum].

Tatnall, A., \& Gilding, A. (1999). Actor-network theory and information systems research. $10^{\text {th }}$ Australasian Conference on Information Systems (ACIS), Wellington, Victoria University of Wellington.

\section{Biographies}

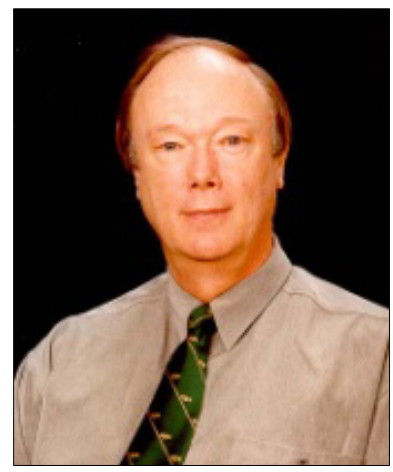

Arthur Tatnall is an Associate Professor in the School of Management and Information Systems at Victoria University in Melbourne, Australia. He holds degrees in Science, Education and Computer Science and has a research Master of Arts in which he explored the origins of Information Systems curriculum in Australian universities. His $\mathrm{PhD}$ involved a socio-technical study in curriculum innovation in which he investigated the manner in which Visual Basic entered the curriculum of an Australian university. His research interests include technological innovation, history of technology, information systems curriculum, project management, electronic commerce, and information technology in educational management. He is Editor-in-Chief of the International Journal of Actor-Network Theory and Technological Innovation, the Journal of Education and Information Technologies and the Journal of Business Systems, Governance and Ethics.

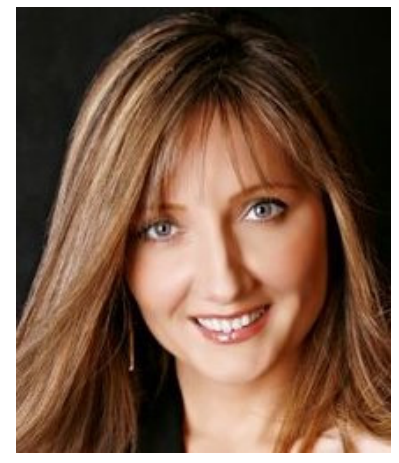

Eva Dakich is a lecturer and researcher at the School of Education at the Faculty of Arts, Education and Human Development, Victoria University in Melbourne, Australia. She is the Co-Cordinator of the Quality Portfolio for Research and Postgraduate Research Degrees at the School of Education. She teaches in the Bachelor of Education and the Master of Education Programs and supervises research students across three faculties. Eva's PhD focused on the links between teachers' digital literacy and pedagogical practices in contemporary primary schools. Her research interests include new learning environments, digital epistemologies, global e-inclusion, mixed-methods research and Delphi designs. 